\title{
VIOLÊNCIA, PRECARIEDADE, NECROPOLÍTICA E DESIGUALDADE SOCIAL EM ESPAÇOS URBANOS
}

\author{
João Vitor Schmutzler Abrahão \\ Autor correspondente. Universidade Federal do Estado do Rio de Janeiro. Avenida Pasteur, 458 - Botafogo. Rio de Janeiro/RJ, Brasil. \\ CEP 22290-240. http://lattes.cnpq.br/4818349504538459. https://orcid.org/0000-0003-0787-6622. bibovitor@gmail.com \\ Francisco Ramos de Farias \\ Universidade Federal do Estado do Rio de Janeiro. Rio de Janeiro/RJ, Brasil.
}

RESUMO

As cidades são espaços urbanos complexos pelas diferenças geográficas, sociais e econômicas, as quais são responsáveis por convulsões e caos. Objetiva-se refletir sobre a distribuição desigual da precariedade em diferentes regiões do espaço urbano, na condição de técnicas que concorrem para a submissão e coisificação dos corpos encerrando-os na rubrica de mercadorias mediante o controle das populações que aciona estratégias de poder decorrendo em segregação e hierarquização social. Por intermédio dessas táticas realiza-se, no cenário moderno do capitalismo, o ajustamento visando à acumulação dos homens, de maneira análoga à acumulação do capital. Da aplicação do biopoder resulta a expansão desordenada de determinados grupos humanos à custa de forças produtivas e da repartição diferenciada do lucro. De resto, problematiza-se, utilizando o método de revisão bibliográfica, privilegiando uma linha de pensamento com destaque à precariedade revestida de vulnerabilidade, considerando vidas descartáveis não passíveis de luto e vidas protegidas. Em seguida, questiona-se a função dos equipamentos e serviços urbanos disponíveis em determinados bairros. Concluímos que o biopoder não é apenas um poder centralizado em uma autoridade governamental, personificada em grande algoz de determinados grupos, visto que se trata de uma malha na qual o poder se capilariza e determina, por meio de ajustes sociais, cotas maiores de precarização em determinados segmentos sociais e cotas menores em outros. Por fim, alude-se que as evidências referidas convergem para pensar o âmbito da necropolítica, fundamentada especialmente em questões raciais, utilizada para justificar o contexto de vidas matáveis.

Palavras-chave: Cidades; biopoder; precariedade; necropolítica; memória social.

VIOLENCE, PRECARIOUSNESS, NECROPOLITICS AND SOCIAL INEQUALITY IN URBAN SPACES

Cities are complex urban spaces due to geographical, social and economic differences which are responsible for upheavals and chaos. Our objective is to reflect on the unequal distribution of precariousness in different regions of the urban space, in relation to techniques that contribute to the submission and objectification of bodies, considering them commodities through the control of the population that trigger power strategies resulting in segregation and social hierarchy. Through these tactics, in the modern scenario of capitalism, the accumulation of men takes place in a similar manner to the accumulation of capital. The application of biopower results in the disordered expansion of certain human groups at the expense of productive forces and the different distribution of profit. Besides, we reflect on these topics taking into consideration the bibliographic review method, privileging a line of thought with emphasis on precariousness coated in vulnerability, considering disposable lives not subject to mourning and protected lives. Then, the role of urban equipment and services available in certain neighborhoods is questioned. We conclude that biopower is not just a power centralized in a governmental authority, personified in great executioners of certain groups, since it is a network in which power is capillarized and determines, through social adjustments, higher levels of precariousness in certain social segments and smaller shares in others. Finally, we state that the evidence referred to converges to think the scope of the Necropolitics, based especially on racial issues, used to justify the context of killable lives.

Keywords: Cities; biopower; precariousness; necropolitics; social memory.

Recebido em: 26/9/2020

Aceito em: 13/5/2021 


\section{Humanos e \\ Democracia}

\section{INTRODUÇÃO}

É preciso, antes de esboçar qualquer problematização, situar o recorte a ser considerado em nossas aproximações acerca dos seguintes temas: espaços urbanos, política do biopoder, condição de precariedade e estado de vulnerabilidade. Em torno dessas linhas diretrizes pretendemos articular de que maneira a vida nas cidades é frequentemente atravessada pela incidência da vulnerabilidade em razão de mecanismos que lhe acentuam e, ainda, problematizar a questão da precariedade como condição inerente ao ser humano, trazendo-a para o âmbito da complexidade e dinâmica dos ambientes citadinos, em relação ao desenrolar da vida. Quer dizer, é notória a diferença entre viver em um meio rural, com graus reduzidos de poluição sonora, ambiental, fluxo menor de pessoas, e a vida nas grandes cidades marcada por ritmos frenéticos, considerando também que pessoas de determinados segmentos sociais, em seus percursos de deslocamento, devem se habituar a situações que consistem em, por exemplo, passar muitas horas do dia em um transporte, em circunstâncias que interferem negativamente no bem-estar e na saúde.

As cidades, na qualidade de espaços não naturais, uma vez criadas como projetos audaciosos motivados pela aspiração humana de uma vida melhor e a pretensão ilusória de o ser humano dominar a natureza, caracterizam-se pela complexidade e heterogeneidade devido à, principalmente, três aspectos intimamente relacionados.

Em primeiro lugar, os espaços urbanos, como organismos em contínua evolução e decadência, são palcos de grandes transformações inerentes ao seu percurso em razão da necessidade de se acomodarem às consequências advindas do progresso científico, cujos rastros modificam potencialmente o modus vivendi produzido a partir, para citar apenas um exemplo, do advento da roda e dos artefatos originados por essa descoberta, como os meios de locomoção e a estruturação de vias de circulação, conforme assinala Abrahão (2018, p. 26), ao afirmar que "as cidades, desde as suas origens, são organismos vivos com redes intrincadas de relações que fazem parte da história da humanidade". Trata-se de um organismo vivo no qual as pessoas paulatinamente constroem seus territórios existenciais com projeções de seus ideais representados na dimensão dos grandes monumentos arquitetônicos, paisagens urbanas, espaços relegados politicamente ao esquecimento, além do ofuscamento causado pelos brilhos estéticos. A esse respeito nos alerta Mejía (2012, p. 2) que:

O espaço urbano não só é atravessado por segmentos binários: classes sociais, gêneros, gerações, espacialidades, etc., ele implica também uma função subjetiva. As cidades nos interpelam, acionando e modelizando intensidades, perceptos, suvenires. A aventura própria das cidades consiste em produzir um espaço feito de exterioridades, compreende a experimentação ampliada e intensificada da alteridade, um devir estrangeiro de cada um, um interstício subjetivo.

Convém admitir que a cidade só é considerada viva em virtude da existência de cenários que têm efeitos em seus circuitos, tanto arquitetônicos quanto humanos, os quais conjuntamente formam uma rede de interação contínua, incidindo diretamente na constituição da subjetividade. Quer dizer, os fluxos urbanos podem ser comparados a linhas de uma grande rede, cujos nós móveis seriam as pessoas e os meios de transporte e os nós fixos correspondem ao conjunto de prédios, edifícios, monumentos, praças, parques, casas, entre outros. 
Ainda cabe acrescentar que no tocante ao espaço habitado relativo à acomodação de pessoas, cada cidade, de certo modo, mantém ressonâncias com outras, sendo esse um aspecto que transcende o espaço na qual se constitui, ou seja, uma cidade estabelece diálogos com outras cidades, seja do mesmo país, seja de países estrangeiros. Mesmo que consideremos as peculiaridades de cada urbe existem pontos em comum, principalmente com relação às maIhas urbanas que conferem à cidade o seu dinamismo, compreendido sob a égide de grande desordem urbana causada, sobretudo, pela desigualdade social preconizada e estabelecida pelas políticas neoliberais. A esse respeito, vale salientar que a violência urbana é somente a ponta visível de um iceberg relacionado à desordem no âmbito das relações sociais, mas que mantém ecos e ressonâncias com o setor econômico que se beneficia desse estado de caos em prol da produtividade e do acúmulo de capital para setores privilegiados da sociedade.

Em segundo lugar, situamos o dinamismo decorrente da massa de pessoas que fazem parte do seu cotidiano, em um processo de interação com efeitos múltiplos e recíprocos, tanto para as estruturas edificadas quanto para seus habitantes. Cabe mencionar que as cidades, desde as remotas eras, precaveram-se em uma preocupação de defesa, com a demarcação de suas bordas por grandes muralhas, com sentinelas aptos e eficientes em garantir sua segurança. Embora, nos dias atuais, não tenhamos mais a construção de grandes muralhas de separação, sabemos que algumas fronteiras podem ser nitidamente traçadas por tratados de intimidação. Convém salientar que as cidades, ao se formarem, trouxeram para o âmbito da experiência humana a ideia da existência de invasores contra os quais fazia-se e faz-se necessário uma vigilância constante na crença de que existem inimigos sempre à espreita.

Em terceiro lugar, a ação dos usuários dos espaços urbanos tem consequências na alteração de suas paisagens arquitetônicas sujeitas ao desgaste e mal preparadas para determinadas intempéries da natureza. Além disso, as diferentes redes necessárias às condições de vida na cidade não só alteram o seu dinamismo, como interferem radicalmente na sua arquitetura, traduzindo-se em objetos pouco comuns, porém imprescindíveis, à convivência humana. Nesse sentido, esses cenários têm efeitos decisivos no tocante à acomodação de pessoas em espaços urbanos, pois conforme assinala Rolnik (1999, p. 100), "a exclusão territorial na cidade brasileira é mais do que a imagem da desigualdade, é a condenação de toda a cidade a um urbanismo de risco".

Como pode ser depreendido a estrutura como as cidades, principalmente de caráter industrial, vêm se modelizando, criam um terreno propício à reprodução do capital, constituindo esse um aspecto que tem pelo menos dois desdobramentos evidenciados. Por um lado, o acúmulo de capital em mãos de poucos possibilita usufruir melhor e mais das benesses da vida. Por outro, a desigualdade social decorrente do capitalismo é escamoteada e negada na rubrica de desordem urbana, sem maiores questionamentos. $O$ tratamento diferenciado, no entanto, em termos de política pública, a determinados segmentos sociais não é objeto de discussão na mesa dos gestores que planejam e pensam o dinamismo dos grandes centros urbanos, ou seja, diante de condições adversas, as pessoas que não dispõem de condições para enfrentá-las facilmente engrossam a fila de matabilidade, conforme propôs Mbembe (2016). Seria correto afirmar que na proporção em que se defende o progresso da cidade, inversamente progride a resistência social de pessoas em condições de vulnerabilidade, resistindo para sobreviver. 
Por esse prisma, podemos comparar as cidades a organismos vivos complexos e heterogêneos: surgem, desenvolvem-se, transformam-se, entram em decadência, subsistem e desaparecem. Cumprindo as etapas de um processo, as cidades estão sujeitas a praticamente todas as vicissitudes relativas aos seres vivos, estando, no mundo em que vivemos, praticamente integradas à vida dos seres humanos: é impossível pensar o planeta Terra sem as inúmeras cidades que nele estão incrustadas, motivo pelo qual alteraram indelevelmente a sua superfície.

Desse modo, as cidades representam para a natureza uma grande perda com possibilidade remota, ou mesmo nenhuma, de recuperação das condições até então existentes. Eis o preço, então, da intervenção humana no planeta sob a égide do que se denomina progresso. Aliás, conforme pontua Lorenz (1974), em um alerta estonteante, na obra Civilização e Pecado, podemos entender as cidades na rubrica de um dos oito erros capitais do ser humano cujas consequências são observadas no processo de devastação e destruição de florestas, utilização excessiva das reservas de recursos naturais, o aquecimento global e, sobretudo, a ausência de ecossistemas em determinadas regiões que inviabilizam a possibilidade de vida. Essa vertente da nossa reflexão nos inclina a recorrer a Stengers $(2015$, p. 47) ao afirmar que:

A contemporaneidade desse duplo devir planetário não tem nada de casual: a brutalidade de Gaia corresponde à brutalidade daquilo que a provocou, a de um "desenvolvimento" cego às suas consequências, ou, mais precisamente, que só leva em conta suas consequências do ponto de vista das novas formas de lucro que elas podem acarretar.

A esse respeito faz-se necessário um esclarecimento: as pegadas do progresso que concorreram para o franco desenvolvimento da livre empresa não se encontram desatreladas do planejamento de um Estado voltado ao privilégio de determinados segmentos sociais, principalmente se considerarmos a utilização de estratégias para assegurar a circulação do capital, mesmo que à custa de um esquecimento proposital de que existem vidas em determinadas camadas sociais que não são sequer toleradas ou mesmo consideradas.

Não ignoramos, contudo, que as cidades se traduzem, sob certa ótica, em benefícios à vida, no entanto têm como contrapartida inúmeros prejuízos, por vezes inevitáveis e irreversíveis.

Lugar por excelência de antagonismos e de paradoxos, os ambientes urbanos surgem estimulados pelo consumo, excesso, ideal de vida melhor e consequente acumulação, características que contribuem de forma primordial na sua mais marcante singularidade: a produção contínua de restos e dejetos, tanto materiais quanto humanos, os quais não encontram meios de serem acondicionados. Assim, em termos habitacionais, algumas vidas são mais protegidas do que outras, mostrando-se também aspectos que marcam decisivamente a vida de seus habitantes. Por esse motivo, reiteramos que as cidades são formas de vida fundamentais ao transcurso de existência do ser humano e, desse modo, as políticas de habitação não podem desconhecer certas prerrogativas éticas, mesmo que se trate de um direito, conforme assinalam Colombo, Silva e Graziano Sobrinho (2018).

Tomando como objeto de análise o dinamismo das cidades em seus diferentes aspectos, para a reflexão pretendida, circunscrevemos a heterogeneidade. Em princípio é preciso indicar que esse aspecto das cidades é politicamente determinado em virtude de questões de 


\section{Humanos e \\ Democracia}

natureza econômica e da alocação de determinados segmentos sociais em nichos diferenciados, principalmente de serviços. Assim, são notórias as diferenças entre algumas regiões que oferecem qualidade de vida infinitamente superior em comparação a outras, em verdadeiras situações de abandono e carência, as quais foram condenadas à segregação, que se cumpre em diferentes níveis: econômico, político, higienista, eugênico, racial, entre outros.

É fundamental entender que esse caráter heterogêneo é mantido, de um modo geral, como uma condição necessária ao andamento das cidades, pois existe um segmento que dispõe de grande poder aquisitivo e outro que não. Sem dúvida, o segmento em marcantes condições de precariedade acaba por se enfileirar em um processo de sujeição à medida que se coloca à disposição para prestar serviços ao segmento do setor abastado como uma possibilidade de sobrevivência, sem ter consciência de que, a cada dia, caminha para sua própria derrocada. Entre as diminutas relações de reconhecimento entre esses dois segmentos destaca-se a possibilidade da utilização da força física de trabalho, ou seja, são estranhos que convivem frente a frente algumas horas por dia. Embora o prestador de serviço tenha certo conhecimento e familiaridade da vida do seu patrão, a recíproca não é verdadeira, pois com raríssimas exceções o patrão sequer sabe onde mora seu empregado e muito menos como vive.

Eis o contexto no qual vivem os atores sociais de uma grande cidade: uns têm a sua disposição condições mínimas de proteção contra a vulnerabilidade por serem minimamente atingidos pela maior parcela da distribuição desigual da precariedade. Situação oposta aplica-se aos outros. Não obstante, esse binarismo não pode ser pensado como uma consequência natural, visto se tratar de um planejamento político que privilegia determinado segmento social.

As cidades, pela disposição de seus nichos habitacionais, setor administrativo, setor financeiro, áreas de lazer e postos de trabalho conformam regiões mais seguras e vigiadas para se viver, com maiores aparatos de segurança, ao passo que outras são completamente abandonadas e esquecidas, caracterizando-se como zonas perigosas e assim assujeitadas a todos os tipos de crimes e violência cujo destino é a crescente pauperização. Dessa maneira, é possível vislumbrar a grande discrepância, relativa principalmente à desigualdade social e suas consequências, culminando em grupos que vivem em meio à precariedade e vidas que não são passíveis de luto. Conforme assinala Butler (2015), essas pessoas são condenadas a caminharem, a passos largos, rumo ao perecimento e à morte.

Assim, determinada distribuição espacial de aparatos urbanos e de atores sociais, bem como a conformação de diferentes formas e estruturas arquitetônicas criam modos distintos de interação, relacionamento, afetações e, sobretudo, diferentes modus vivendi. A título de ilustração, podemos afirmar que um acontecimento que choca determinada região, e por consequência determinado grupo de uma cidade, pode ser um acontecimento banal, inscrito no cotidiano de outro grupo, que habita outra região. Não só nesse aspecto as cidades se diferenciam, mas igualmente na esfera das necessidades básicas em razão das exigências específicas e sofisticadas de uns e raras possibilidades de escolha de outros. Eis o diferencial no tocante ao entendimento sobre vidas que merecem ser cuidadas e aquelas que são expostas à adversidade decorrente de inúmeras intempéries. 
São essas e outras tantas circunstâncias que configuram o espaço urbano, com seus prós e contras, como locus que acentua sobremaneira a vulnerabilidade de determinados segmentos sociais, ao passo que produz mecanismos protetores para outros. Queremos salientar, contudo, que essa não é uma prerrogativa das cidades e sim a expressão da vontade de seus gestores que, em seu ofício, aguçam a sua escuta apenas para as vozes de um segmento social, beneficiando-o e, ao mesmo tempo, ignorando a existência de outras.

Diante do exposto até então, encaminhamos nossa reflexão considerando que existem regiões da cidade que acentuam a vulnerabilidade do ser humano, especialmente pela distribuição desigual da precariedade. Certamente, essas características humanas ressoam também na vida das cidades, as quais se organizam em polos administrativos a partir de projetos políticos no gerenciamento do seu cotidiano, com o desenvolvimento e aprimoramento de técnicas diversas no intuito de garantir o controle e a dominação de certos agregados de pessoas, ao mesmo tempo que favorece a segurança e bem-estar de outras que se distribuem em espaços faustos de prédios e grandes condomínios.

Eis a expressão mais significativa do biopoder (FOUCAULT, 1988), o qual age por meio de políticas públicas, investimentos, leis e decretos, taxas e impostos, aparatos urbanos, entre outros. O biopoder tem também a capacidade de gerenciar o social, pela vigilância e controle de segmentos populacionais, de acordo com o desejo das instituições e suas disciplinas. Além disso, incide frontalmente sobre a vida, especialmente na delimitação de quais vidas são merecedoras de viver, para servir à produção. Como argumentam Hardt e Negri (2005, p. 43), o "biopoder é a forma de poder que regula a vida social por dentro, acompanhando-a, interpretando-a, absorvendo-a e a rearticulando". Em outras palavras, é possível escolher quais grupos terão acesso a determinados serviços, quais grupos poderão frequentar determinados espaços e até mesmo quais grupos serão qualificados como vidas que merecem viver, da mesma forma que decreta quais grupos têm o acesso a bens culturais bloqueados e via aberta para a morte.

Nesse contexto, a questão que se coloca é a de como pensar o contexto das relações sociais nos espaços urbanos, considerando a lógica do biopoder nas decisões sobre a vida e a distribuição desigual da precariedade inerente às camadas sociais e aos habitats citadinos.

\section{ESPAÇOS URBANOS: DINÂMICA E COMPLEXIDADE}

Ilusora de pessoas

De outros lugares,

A cidade e sua fama

Vai além dos mares

Chico Science

Os espaços urbanos são compostos por uma série de formas e estruturas, as quais engendram cenários típicos de seus ambientes: vias de circulação de pessoas e veículos, praças e jardins, monumentos, áreas de lazer, casas e edifícios, barracos e favelas, terrenos completamente irregulares com a presença de rios, córregos, morros, mangues, aterros, lagoas, entre outros. Compõem também esse cenário os atores sociais na condição de nômades, passantes, moradores, trabalhadores, e ainda suas dinâmicas constituídas por serviços diversos, tais quais: aparatos de segurança e vigilância, serviços médicos, serviços emergenciais, como 


\section{Humanos e \\ Democracia}

corpo de bombeiros e defesa civil e muitos outros. Essa múltipla teia concebida pela complexidade entre aspectos físicos e humanos não só afeta o modus vivendi dos atores sociais, mas também deixa marcas visíveis na paisagem das cidades.

Partindo da conceituação de paisagem como o que pode ser apreendido pela visão, ou seja, tudo aquilo que se encontra no domínio do visível e, ainda pelas cores, pelos movimentos, pelos odores, pelas diferentes tessituras, entre outros (SANTOS, 2014), pode-se então apreender a memória das cidades por meio da paisagem concebida no hibridismo entre seus aspectos físicos e humanos. Sua memória é conservada em plantas, croquis, esboços, traçados de cartas e mapas geográficos, que desde as épocas mais remotas retratam esses ambientes em seus diversos momentos históricos, destacando avenidas, monumentos, ruas, casas e edifícios que sofreram transformações, foram preservados, deixaram de existir ou até mesmo tornaram-se formas em ruínas, meio vivas, meio mortas. Ao se comparar plantas ou mapas de tempos distintos de uma mesma cidade, por exemplo, provavelmente serão constatadas grandes transformações, da mesma forma que é possível verificar ao se comparar fotografias de uma mesma pessoa em diferentes épocas de sua vida. Em outras palavras, equiparando de forma análoga mapas de épocas distintas e fotografias de um ser humano durante as diferentes etapas de sua vida, explicita-se mais enfaticamente o caráter mutável das cidades, as quais se apresentam por esse prisma como um ser vivo dotado de um dinamismo complexo em virtude do qual determinados cuidados fazem-se necessários.

Durante seu percurso de existência, as cidades apresentam-se propensas aos mesmos tipos de efeitos inevitáveis relativos ao decorrer do tempo, como envelhecimento e consequente deterioração, além de consequências de acontecimentos previsíveis, porém inesperados, como acidentes e catástrofes. Assim, como os seres vivos, as cidades necessitam de cuidados e manutenções em seus diferentes aspectos: físico, social, econômico, entre outros. Da mesma maneira que a vida de um ser vivo torna-se penosa e precária na ausência de cuidados e, consequentemente, em um estado degradado de saúde, o mesmo acontece nos ambientes urbanos que não são corretamente preservados: a vida torna-se desagradável e fatigante. Não obstante, os cuidados referidos devem ser considerados como aliados à condição de um viver bem, pois o fim é certo e inevitável: o que varia é o intervalo de tempo de vida útil.

Na tentativa de contornar esses problemas e eximindo-se de realizar a necessária manutenção dos ambientes urbanos, de forma que não se tornem verdadeiras ruínas, são realizadas diversas modificações nas formas e estruturas citadinas no intuito de revitalizá-las, ou seja, dar uma nova vida ao que já é considerado morto. A ideia de revitalização é determinada, sobretudo, por um interesse de natureza econômica que planeja uma transformação com o propósito de circulação de grandes montantes de capital concentrado nas mãos de poucos. Uma curiosidade deve ser ressaltada: as cidades não são decretadas mortas em sua totalidade, apenas algumas regiões são alvo desse processo por motivações diversas.

Diante de um estado de ruínas em algumas regiões de um grande centro urbano, os gestores optam, frequentemente, pela demolição e reconstrução, ao invés de lançar mão de políticas de manutenção e conservação, o que comparativamente poderia representar um ônus econômico e humano muito menor. Nesse sentido, grandes modificações ocorrem como demolições de casas, ruas, viadutos, prédios, remoções de pessoas, abertura de novas vias de 
circulação, entre outros. Essas transformações são mais um fator de agravamento no tocante à precariedade inerente aos ambientes urbanos, uma vez que modificam as dinâmicas dos atores sociais, causam estranhamento e criam novas exigências e modos de vida. Tanto os novos cenários urbanos quanto as novas modalidades de relacionamento social correspondem a exigências de adaptação e ambientação para aqueles que fizerem parte desse processo. Caso contrário serão excluídos, aniquilados e, em algumas circunstâncias, alvos de práticas sociais de eliminação, como o extermínio de moradores de rua e rituais de linchamento.

A metamorfose contínua das cidades e suas consequências potencializam e expõem cada vez mais a vulnerabilidade com a qual os atores sociais devem lidar em seu cotidiano. $\mathrm{O}$ ambiente urbano gradativamente desponta com muito mais exigências do que se verifica no meio rural. O ser que habita as cidades, caso queira continuar fazendo parte delas, deve possuir um gigantesco arcabouço de conhecimentos e técnicas se quiser garantir sua sobrevivência. Deve entender o significado de placas, sinais luminosos, sinais sonoros, estar atento à travessia de ruas e avenidas, saber operar máquinas como elevadores, entre outros. As pessoas nas cidades aos poucos desenvolvem atitudes de apatia em relação a determinados acontecimentos, por exemplo, reagir com indiferença à presença de um cadáver, quer dizer, determinados acontecimentos que deveriam causar indignação, em razão da velocidade que a vida da cidade requer e do crescente anonimato, muitas vezes passam despercebidos ou mesmo ignorados.

Guiados por essa orientação, no intuito de pensarmos o espaço urbano em sua configuração estrutural, recorremos ao pensamento de Brown (2019, p. 64), para quem

[...] o espaço não é apenas uma arquitetura para o poder, mas a cena da imaginação e dos imaginários políticos. Ordenamentos humanos do espaço e os significados atribuídos a esses ordenamentos moldam nossas concepções de quem somos, especialmente na vida com os outros. Esses ordenamentos podem pôr em primeiro plano localidades hemisféricas ou características topográficas: uma nação perde seu mar em acordos de pós-guerra, uma represa transforma um rio em lago, um bairro é cindido pela construção de uma rodovia ou de um muro.

Ao nos alinharmos com o pensamento anterior, somos levados a concluir que o ordenamento de pessoas hierarquizadas por condições socioeconômicas interfere diretamente no ordenamento do espaço, produzindo nichos diferenciados que interagem de forma substancial com a dinâmica dos processos subjetivos. Sendo assim, podemos afirmar que vivemos em territórios marcados por rígidas fronteiras, às vezes físicas, cujas consequências que mais se sobressaem consistem no desenvolvimento de imaginários políticos acerca do que somos, bem como acerca dos outros, como também na ausência desses imaginários que são determinados pela lógica de configuração da malha espacial urbana.

Diante do exposto, constata-se que os meios urbanos, compostos por espaços heterogêneos, tanto no que diz respeito a sua arquitetura como no que se relaciona ao ser humano e seus aspectos sociais, acentuam e potencializam a vulnerabilidade daqueles que o habitam. Existem regiões nas cidades que têm propriedades para proteger aqueles que nelas se encontram, ao passo que outras, potencialmente, expõem as pessoas a severas situações de risco, ameaça e grande probabilidade de morte. Queremos sinalizar, todavia, que essas configurações não são, de longe, obras da natureza, e sim o resultado de ações politicamente engen- 
dradas, visando a determinados fins, sobretudo à manutenção do status quo de um segmento social e à possibilidade de melhoria de vida pelo enriquecimento.

Depreende-se então a seguinte questão: A pluralidade heterogênea em uma grande cidade, com seus conglomerados arquitetônicos e massa de pessoas em condição de desigualdade, pode ser pensada como fenômeno naturalizado, inevitável, ou podemos atribuí-lo a uma necessidade inerente as cidades, que precisa que esses sintomas se tornem latentes para garantir sua condição de subsistência? Em outras palavras, seriam o aumento da vulnerabilidade e a distribuição desigual da precariedade nos ambientes urbanos os fatores que garantem seu funcionamento? Não é possível afirmar com certeza positivamente ou negativamente, entretanto podemos asseverar a existência de dispositivos e mecanismos criados pelo homem que, por meio de instituições e disciplinas, atuam nas populações, definindo, controlando e decidindo aspectos que influenciam fundamentalmente seus modos de vida.

\section{O BIOPODER E SUAS DOBRAS}

Cavaleiros circulam

Vigiando as pessoas

Não importa se são ruins Nem importa se são boas

Chico Science

Se lançarmos um olhar em retrospectiva, do ponto de vista histórico, constatamos que o mundo antigo era regido por uma lógica cujo critério era fundamentado em premissas religiosas, as quais eram assimiladas pelos monarcas, que se equiparavam a verdadeiros deuses na Terra. Assim, difundia-se a ideia de que as pessoas deveriam temer o monarca da mesma forma que temiam a Deus, ou seja, cabia ao monarca, na condição de representante-mor terrestre, legislar e decidir sobre a vida das pessoas que lhe eram subordinadas.

O poder nas mãos do soberano tinha grandes extensões em termos da maior decisão, que consiste em viver ou não. Sendo assim, a vida e a morte das pessoas dependiam da vontade do soberano, que julgava quais ações dos subordinados o afrontavam ou não. Tratando-se do primeiro caso, a ação era considerada criminosa e o autor pagaria com sua própria vida, em um ritual público determinado pelo soberano, para servir de exemplo e intimidação aos demais que porventura pensassem em ir de encontro às suas ideias e caprichos. Somente o soberano conservava o poder de escolha entre decidir pela morte ou deixar viver. Com o passar do tempo esse poder de matar foi se deslocando das mãos do soberano para se transformar em um complemento de um poder exercido por aparatos técnicos disciplinares que se encarregam de modelar e decidir sobre a vida (FOUCAULT, 2014).

Esse novo arsenal de gerenciamento da vida, em seus múltiplos aparelhos, redundou em modalidades específicas de domínio sobre o corpo e principalmente sobre a alma, ficando ao encargo da figura anônima de aparatos estatais que se encarregam de sua dinâmica, pois segundo Foucault (1988, p. 130), "pode-se dizer que o velho direito de causar a morte ou deixar viver foi substituído por um poder de causar a vida ou devolver à morte". Em certo sentido, o deslocamento operado consistiu em transformar o decidir matar pela possibilidade de criar condições em prol da vida. Logo, se antigamente a lógica pautava-se em uma decisão que decretava a morte, atualmente, com o biopoder, pensa-se minimamente na vida. 


\section{Humanos e \\ Democracia}

O biopoder, ou poder sobre a vida, se desenvolveu a partir do século 17 sob duas formas principais: a primeira caracteriza-se pelo desenvolvimento das disciplinas do corpo; já a segunda forma denota as intervenções e regulações da população, denominada por Foucault de biopolítica da população. Assim, as disciplinas do corpo estão ligadas à ideia do corpo como máquina, ao adestramento desse corpo, exploração de suas forças e sua docilização, enquanto a regulação da população designa os processos biológicos e as condições que os fazem variar, tais como nascimento, mortalidade, longevidade, entre outras. Essas duas formas caracterizam um poder que Foucault (1988, p. 131) afirma ter como função mais elevada "não [...] mais matar e sim investir sobre a vida de cima para baixo". Desse modo, as ínfimas expressões da vida são consideradas valiosas no sentido da reversão do projeto de matar. Conforme ressaltam Hardt e Negri (2005), o poder sobre a morte torna-se um poder sobre a vida: o biopoder, característica que podemos considerar, grosso modo, como a grande realização da soberania, foi atualizado para nossos tempos de forma precisa por Mbembe $(2018$, p. 41) como a "capacidade de definir quem importa e quem não importa, quem é descartável e quem não é".

A regulação e o gerenciamento sobre a vida e o dinamismo das populações fazem parte de um projeto relacionado ao biopoder que, conforme expõem Hardt e Negri (2005, p. 43), "se refere a uma situação na qual o que está diretamente em jogo no poder é a produção e a reprodução da própria vida". Dessa forma, surgem diversas disciplinas e determinadas práticas políticas e econômicas relativas a problemas de natalidade, saúde pública e habitação, por exemplo, com o consequente aparecimento de diversas técnicas que visavam à sujeição dos corpos e ao controle das populações.

O conceito de biopoder engendrado por Foucault (1988, p. 132) foi caracterizado como "elemento indispensável ao desenvolvimento do capitalismo, (...) garantido à custa da inserção controlada dos corpos no aparelho de produção e por meio de um ajustamento dos fenômenos de população aos processos econômicos", ou seja, suas formas e procedimentos múltiplos, presentes no corpo social e mantido por diversas instituições, garantem a manutenção das relações de produção, hierarquização, dominação, segregação e acumulação desigual no corpo social. Dessa forma, "já não se trata de pôr a morte em ação no campo da soberania, mas de distribuir os vivos em um domínio de valor e utilidade" (FOUCAULT, 1988, p. 135), que, na condição de máquinas operantes, devem ser efetivas para não pôr em risco a circulação do capital. Em última instância, a lógica primeva do biopoder pressupõe a manutenção de uma vida, não exclusivamente pensada para o ser humano, e sim como um artefato de grande valia para garantir, em termos produtivos, as dinâmicas do sistema econômico.

Depreende-se, pois, do pensamento de Foucault, que as engrenagens do biopoder funcionam, de certo modo, para fomentar e levar a termo o processo de distribuição de vidas em escalas diferenciadas de valores, consequentemente tendo como meta a utilidade. Disso resulta uma configuração de seres humanos bastante heterogênea, o que se acentua na medida em que tomamos como foco de análise a complexidade dos centros urbanos, em termos de seus contornos específicos, ou seja, áreas de risco e outras que representam ameaças à vida.

Em meio à heterogeneidade dos meios urbanos torna-se nítida essa distribuição desigual dos seres humanos, divididos segundo determinados interesses, por via política ou mesmo econômica, caracterizando-se o exercício de um biopoder geográfico relativo a uma distri- 
buição desigual do e no espaço. Nesse ponto, julgamos necessário lançar um questionamento relativo a essa reflexão: Por que determinado bairro é escolhido para tornar-se uma região desenvolvida e bem servida de serviços e infraestrutura, reservada a uma elite social e econômica, enquanto outros são, pelo contrário, escolhidos para o abandono e exclusão, na medida em que seriam a parcela da população que na realidade é a que mais necessita de serviços e equipamentos urbanos que forneçam um mínimo de desenvolvimento e assistência social?

Certamente, não temos uma resposta para essa difícil questão, mas podemos enveredar por algumas trilhas, iniciando pelos interesses econômicos que regulam diretamente setores da atividade privada e, indiretamente, o setor público. Essa é apenas uma pista. Obviamente, do ponto de vista da estratificação social, existem poderosos mecanismos para manter um segmento de alto poder aquisitivo em satisfatórias condições de vida, criando condições para que essas pessoas progridam economicamente em suas vidas. A contrapartida desse processo é a pauperização da população deixada propositadamente à margem para se constituir, principalmente, em mão de obra barata no intuito de favorecer e possibilitar o enriquecimento da classe social dominante. Desse modo fica decretado, por intermédio desse biopoder, quais vidas estão na linha de frente de preservação e aquelas que se encontram no limiar do aniquilamento.

Dando sequência a nossa reflexão, podemos afirmar que, por meio de dispositivos econômicos, é possível "manobrar" populações ao aumentar, por exemplo, o preço de taxas e impostos sobre o uso da terra, como o ITR e o IPTU, causando um efeito cascata que acaba por aumentar na mesma proporção aluguéis, preços de imóveis, custo de vida, criando um cenário ideal para que a gentrificação, conforme assinala Smith (1996), e seus efeitos perversos aflorem, removendo grupos inteiros por meio da segregação econômica.

Já mediante a via política, pode-se por meio de decretos e leis decidir quais grupos serão removidos e quais bairros serão reformados visando a determinados interesses, os quais, quase sempre, têm um pano de fundo econômico. Além disso, existe ainda o fato de que há regiões que são privilegiadas pela administração pública enquanto outras não o são, e assim, muitas vezes no afã de justificar medidas decorrentes desse investimento desigual é necessário criar uma "população-outra", da mesma forma que se criam "regiões-outras" das cidades, geralmente caracterizadas negativamente, em diversos sentidos, visto que, da mesma forma que se difunde a ideia acerca da existência de regiões perigosas ante a conotação de serem foco de contágio ou concentrarem alto índice de criminalidade, difunde-se também a ideia de que existem classes sociais perigosas, conforme assinala Coimbra (2001).

O resultado dessas operações é historicamente conhecido: regiões das cidades que passam a ser evitadas e temidas, razão pela qual há uma grande desvalorização e grupos estigmatizados por justificativas geralmente relacionadas à segurança pública ou mesmo questões higienistas, no intuito de classificar populações indignas de receber esses mesmos investimentos, como se fossem não merecedoras do tratamento idealizado para um dado segmento social em termos de serviços, lazer, entretenimento, habitação e espaços requintados de convivência. Seguindo essa linha de raciocínio, valemo-nos da contribuição de Hardt e Negri (2005, p. 142) de que, nas cidades "a alteridade não é dada, é produzida", o que nos leva a compreender que, tanto a heterogeneidade da arquitetura de uma cidade, quanto a de seus habitantes é o resultado de um projeto político cujo planejamento assenta-se em premissas 


\section{Humanos e \\ Democracia}

voltadas para mecanismos protetores da vulnerabilidade para alguns habitantes, enquanto que outros mecanismos extenuam a vulnerabilidade de pessoas que se concentram em grandes "amontoados" nas periferias dos centros urbanos e demais regiões seladas por conotações negativas, como as favelas.

Esse fato por si só já caracteriza a cidade como um habitat produtor de uma heterogeneidade no que respeita aos níveis de precariedade, ou seja, populações cuja situação geográfica acentua ainda mais a vulnerabilidade de suas condições. Em outras palavras, "a precariedade enfatiza nossa substituibilidade e nosso anonimato radicais em relação tanto a determinados modos socialmente facilitados de morrer e de morte, quanto a outros modos socialmente condicionados de sobreviver e crescer" (BUTLER, 2015, p. 32). Caberia, a esse respeito, uma indagação: Qual o intuito dos aparatos estatais em distribuírem desigualmente a precariedade a ponto de expor umas pessoas a um maior grau de vulnerabilidade? E, ainda, que indicadores nos levam a pensar nesses aspectos?

Se analisarmos uma cidade em uma visão panorâmica, não podemos evitar de confrontar o nosso olhar com marcantes contrastes, tanto arquitetônicos quanto humanos: as regiões das grandes cidades não têm as mesmas cores, as mesmas árvores, os mesmos odores e não convivem com os mesmos sons. A título de ilustração, recorremos aos bairros do subúrbio distante, que geralmente têm instalações sanitárias precárias, rios poluídos a céu aberto, quase sempre não possuem hospitais com atendimento emergencial, fazendo com que para conseguir esse tipo de atendimento as pessoas precisem deslocar-se para outras regiões. Quer dizer, considerando o atendimento médico a uma pessoa que more em bairros bem assistidos de serviços, temos uma nuance completamente diferente quando comparamos, por exemplo, com uma pessoa que more em áreas periféricas ou favelas encravadas no alto de morros, que necessitem uma urgência médica, especialmente ilustrado pelo âmbito geográfico por uma cidade como o Rio de Janeiro. Caso essa pessoa seja acometida por um mal súbito e precise de um resgate rápido, tanto ela como os administradores públicos já sabem, de antemão, não ser possível atendê-la em tempo hábil, ocasionando certamente a sua morte. Sobre esse aspecto, Butler (2015, p. 46) afirma que:

A condição precária designa a condição politicamente induzida na qual certas populações sofrem com redes sociais e econômicas de apoio deficientes e ficam expostas de forma diferenciada às violações, à violência e à morte. Essas populações estão mais expostas a doenças, pobreza, fome, deslocamentos e violência sem nenhuma proteção.

De certo modo, os contornos estruturais de uma cidade já traçam uma linha demarcatória em relação ao biopoder, no sentido de que disponibilizam de mecanismos de atenção em uma região, os quais se encontram, de forma precária ou ausente, em outras, acentuando, sobremaneira, a vulnerabilidade das pessoas que habitam esses espaços. É curioso notar que certas regiões dispõem de serviços, tanto da iniciativa privada quanto estatais para coibir o retorno ou acesso de pessoas excluídas sob a alegação de que são uma fonte de perigo, seja pela ideia de um contágio em termos de doenças, seja pela crença de que essas pessoas apresentam potencial criminoso. De uma maneira ou de outra, a mensagem passada a essas pessoas é a de que elas não são vidas que merecem atendimento, cuidado, proteção e, portanto, não devem sobreviver, tampouco coabitarem determinadas regiões as quais, política e 
economicamente, foram configuradas a partir de um ideal que traça a fronteira entre aqueles que devem ser incluídos e os que devem ser segregados.

Essa última categoria não se encontra incluída no rol daquelas pessoas que têm vidas passíveis de luto da mesma forma que outras. Diante disso, esses habitantes das cidades expostos à vulnerabilidade necessitam ser capazes de se flexibilizarem de acordo com as peculiaridades advindas dessa biopolítica que, de forma contraditória, fornece as mínimas condições para sua sobrevivência, ao passo que, comandada pelos interesses relativos a determinadas políticas e ao mercado financeiro, precariza cada vez mais suas condições de vida, conforme assinala Butler (2018, p. 21):

De fato, estamos no meio de uma situação biopolítica na qual diversas populações estão cada vez mais sujeitas ao que chamamos de "precarização". Geralmente induzido e reproduzido por instituições governamentais e econômicas, esse processo adapta populações, com o passar do tempo, à insegurança e à desesperança; ele é estruturado nas instituições do trabalho temporário, nos serviços sociais destruídos e no desgaste geral dos vestígios ativos da socialdemocracia em favor das modalidades empreendedoras apoiadas por fortes ideologias de responsabilidade individual e pela obrigação de maximizar o valor de mercado de cada um como objetivo máximo de vida.

Concluindo nossa linha de pensamento, é possível relacionar a distribuição desigual da precariedade e sua intensificação, que leva a graus acentuados de vulnerabilidade, a procedimentos múltiplos relacionados a determinadas políticas, com panos de fundo econômicos, as quais agem no controle de populações por meio de instituições com a finalidade de favorecer uns em detrimento de outros. Em outras palavras, o biopoder e suas instituições atuam nas cidades, de forma a manter determinadas pessoas com seus privilégios, ao passo que mantêm outras em situação de desamparo, vulnerabilidade e precariedade, gerando dejetos e restos humanos.

\title{
4 A PRECARIEDADE NO ÂMAGO DA EXPERIÊNCIA HUMANA
}

\author{
E o mulambo já voou, \\ Caiu lá no calçamento, \\ Bem no sol do meio-dia \\ O carro passou por cima \\ E o mulambo ficou lá \\ Mulambo eu, mulambo tu
}

Chico Science

Considerando o aspecto constitutivo do ser humano, suas células, tecidos, órgãos e sistemas, ou seja, seu organismo de uma maneira geral, torna-se possível inferir que seu corpo o inscreve no campo da precariedade por sua própria natureza, visto que essa dinâmica apresenta exigências em termos de condições para se manter minimamente em estado de equilíbrio. O corpo humano não é autossuficiente, quer dizer, marcado pela dependência ao exterior, necessita de suprimentos, cuidados e o mínimo de atenção e zelo, desde seu primeiro batimento cardíaco, no interior do ventre que o gera, até o último, o qual decreta o fim de sua precariedade e por isso também o de sua existência, pois "afirmar que uma vida é precária exige não apenas que a vida seja apreendida como uma vida, mas também que a 


\section{Humanos e \\ Democracia}

precariedade seja um aspecto do que é apreendido no que está vivo" (BUTLER, 2015, p. 30). A precariedade é condição de existência da vida humana e como bem assinala Butler (2015, p. 40), "exige apoio e condições possibilitadoras para poder ser uma vida vivível". Além disso, como organismo vivo, e dessa forma, inscrito no campo da materialidade, o corpo está sujeito ao perecimento e extenuação, devido à sua inevitável finitude, a qual o insere também no âmbito do desamparo. Em outras palavras, a partir do momento em que se insinua uma vida, esta torna-se duplamente condenada por sua precariedade e desemparo, uma vez marcada pela incompletude, propriedade do corpo em relação à qual, pouco ou nada, o organismo vivo tem a fazer, a não ser buscar satisfação na ilusão de encontrar meios de completude.

A situação de incompletude do corpo pode analogamente ser considerada na abordagem que fazemos sobre as cidades, ou seja, podemos fazer a extensão desse entendimento para compreender a dinâmica dos ambientes citadinos.

Da mesma forma, seguindo o curso de nossa atual reflexão, podemos denominar as cidades como ambientes imersos em precariedade pois, partindo da exortação de Butler (2015, p. 31) de que a precariedade "implica viver socialmente, isto é, o fato de que a vida de alguém está sempre, de alguma forma, nas mãos do outro", e refletindo sobre o modo de vida nos meios urbanos como grande aglomerado de pessoas que são, voluntariamente ou não, obrigadas a participar das mesmas dinâmicas, reunidas de maneira muito mais aproximada que no meio rural, por exemplo, podemos entender a vida nas cidades como fator de acentuação máxima da precariedade. Isso significa que, citando Tuan (2005, p. 251), as cidades "não são 'paus e pedras', mas uma complexa sociedade de pessoas heterogêneas vivendo perto umas das outras" as quais se caracterizam, dessa maneira, como uma "soberba realização humana" que, justamente por essa heterogeneidade, "é também condição que incentiva o conflito".

Em meio Pa precariedade inerente a essa vida citadina composta por instituições e dispositivos que funcionam na regulação e controle das populações que habitam as cidades, certos valores são disseminados causando estranhamento e até mesmo ausência de reconhecimento de alguns atores sociais. $O$ ponto de partida nesse processo consiste em imputar a determinadas populações o caráter animalesco, incivilizado, sem hábitos higiênicos, sem erudição. Tudo isso resulta em um processo de desqualificação e desapropriação. Alguns deles, como miseráveis e moradores de rua em situação de risco, a título de exemplo, nem mesmo são considerados como seres humanos, dotados da mesma precariedade e desamparo, e dessa forma avolumam a rubrica de seres indesejáveis e repugnantes. Nessa condição, têm sua vulnerabilidade elevada a níveis estratosféricos, chegando ao ponto de as cidades criarem formas e estruturas visando a excluir essas pessoas dos centros urbanos, caso da denominada arquitetura hostil, que se apresenta por meio de pedras pontiagudas estrategicamente posicionadas embaixo de viadutos e pontes, bancos de praças com barras de metal para impedir que seja possível se deitar neles, flashes de luzes piscantes na frente de edifícios e portas de lojas, entre outros.

Determinados enquadramentos permitem que pessoas sejam coisificadas e que dessa maneira possam sofrer sem que isso seja um problema para os outros atores sociais que continuam suas vidas sem maiores problemas, até mesmo perpetuando essas atitudes hostis. Consoante ao pensamento de Butler $(2015$, p. 13), "se certas vidas não são qualificadas como vidas [...] então essas vidas nunca serão vividas nem perdidas no sentido pleno dessas pala- 
vras", quer dizer, essas pessoas vivem vidas miseráveis, agravadas por esses ambientes urbanos hostis, não sendo nem mesmo consideradas vidas, morrendo de doenças e frio sem que isso cause maiores alardes ou grandes comoções.

As cidades, assim, constituem-se em ambientes predatórios em que certos grupos, os quais se constituem mais humanos que outros, agem sobre outros grupos, coisificando-os, utilizando-se de diferenças regionais, econômicas, de escolarização e até mesmo raciais, na construção de desigualdades que preenchem o locus urbano. Como aponta Mbembe (2018, p. 18), "na economia do biopoder, a função do racismo é regular a distribuição da morte e tornar possíveis as funções assassinas do Estado", ou seja, o racismo é uma das diversas tecnologias utilizadas no exercício do biopoder nos espaços urbanos, acentuando a vulnerabilidade dos atores sociais que o habitam.

Em meio a esse cenário de acentuação de vulnerabilidades, o que se apresenta como marca indelével das cidades é a distribuição diferencial da condição de precariedade que, para Butler (2015, p. 45-46), configura-se como uma questão "material e perceptual, visto que aqueles cujas vidas não são "consideradas" potencialmente lamentáveis e, por conseguinte, valiosas, são obrigados a suportar a carga da fome, do subemprego, da privação de direitos legais e da exposição diferenciada à violência e à morte".

Dessa forma, a precariedade humana é afetada sobremaneira por esses aspectos relativos ao espaço geográfico, o qual vai se modificando devido às dinâmicas das sociedades humanas e sua organização administrativa e econômica, adquirindo contornos políticos no que se refere à manutenção de privilégios direcionados a determinados grupos por dispositivos biopolíticos, que garantem essa distribuição desigual da precariedade. Isso significa que, como afirma Butler (2015, p. 46-47): "a condição precária também caracteriza a condição politicamente induzida de maximização da precariedade para populações expostas à violência arbitrária do Estado que com frequência não têm opção a não ser recorrer ao próprio Estado contra o qual precisam de proteção".

Por fim, após essa reflexão sobre a precariedade da vida humana e seus desdobramentos relativos ao agravamento na vida das grandes cidades, e principalmente, considerando sua distribuição desigual que leva a níveis distintos de vulnerabilidade a diferentes atores sociais, é possível traçar algumas considerações.

\section{CONSIDERAÇÕES}

Em vista das reflexões realizadas, intentamos compreender de que maneira a inter-relação entre os dispositivos e tecnologias do biopoder, a vida nas cidades e a condição de precariedade inerente à vida humana se apresentam.

Primeiramente, explicitamos os ambientes urbanos, abordando suas características no que respeita as suas complexidades e dinamismo. Dessa forma, consideramos o espaço urbano como algo vivo para assim pensar as transformações por meio de diferentes processos que, por meio de dinâmicas entre formas, funções e processos, suscitam transformações espaciais que impactam diretamente no contingente de atores que o habitam. Esses processos de transformação urbana nos revelam então que para sua concretização são utilizados diver- 
sos tipos de justificativas, as quais amenizam os danos subjetivos aos atores sociais, por meio de argumentos que, de alguma maneira, ocultem sua carga de culpa ou responsabilidade.

Em seguida, tecemos um sucinto histórico sobre o biopoder e a maneira como ele se modificou no decorrer da História. A lógica do biopoder moderno, não mais relacionada à decisão soberana de matar ou não, mas sim em prol da vida, visa menos à vida enquanto um atributo do ser humano do que a sua prontidão para fazer funcionar a máquina forjada pelo capital, ou seja, deve-se viver não para desfrutar da vida e sim para produzir e consumir desenfreadamente.

Observamos, no que diz respeito à precariedade, que esta é inerente à vida humana desde seu aspecto biológico até a questão social de sua vida estar sempre na mão do outro. Nas cidades, em grande proporção, existe uma distribuição desigual da precariedade, o que faz com que determinados grupos sociais, dependendo de certos fatores como local de residência, poder aquisitivo, ou mesmo da cor da pele tenham sua vulnerabilidade acentuada. Essa má distribuição gera vidas que não são passíveis de luto e que, por isso, não são vidas consideradas dignas de sobrevivência.

Por fim, almejamos contribuir com a reflexão realizada sem a pretensão de encerrar ou chegar a conclusões estanques. Pretendemos o prosseguimento da discussão no sentido de intentar, de alguma maneira, compreender essas complexas dinâmicas que fizeram e fazem parte da vida humana nas grandes cidades com a finalidade de contribuir, de alguma forma, para a elaboração de alternativas a esse cenário biopolítico urbano, no intuito de amenizar a condição de precariedade e desamparo que inevitavelmente são intrínsecos à vida humana.

\section{REFERÊNCIAS}

ABRAHÃO, J. V. S. Memórias do Porto Maravilha: o eclipsamento de violências traçado por elegâncias estéticas. 2018. Dissertação (Mestrado em Memória Social) - Programa de Pós-Graduação em Memória Social, Universidade Federal do Estado do Rio de Janeiro, Rio de Janeiro, 2018.

BODY-GENDROT, S. Globalização, medo e insegurança. São Paulo: Edusp, 2018.

BROWN, W. Nas ruínas do Neoliberalismo. São Paulo: Politeia, 2019.

BUTLER, J. Quadros de guerra. Rio de Janeiro: Civilização Brasileira, 2015.

BUTLER, J. Corpos em aliança e política das ruas. Rio de Janeiro: Civilização Brasileira, 2018.

COIMBRA, C. Operação Rio: o mito das classes perigosas. Rio de Janeiro: Intertexto, 2001.

COLOMBO, G.; SILVA, P.; GRAZIANO SOBRINHO, S. F. C. Urbanização, segregação socioespacial e violência na cidade: reflexões introdutórias. In: CARVALHO, C. O.; GRASSI, K.; GRAZIANO SOBRINHO, S. F. C. (org.). Vidas urbanas e a vida nas cidades: regramentos urbanos, ambientais, seletividade e violência. Caxias do Sul: Educs, 2018. FOUCAULT, M. História da sexualidade I: a vontade de saber. Rio de Janeiro: Edições Graal, 1988.

FOUCAULT, M. Vigiar e punir: nascimento da prisão. Petrópolis: Vozes, 2014.

FOUCAULT, M. Microfísica do poder. Rio de Janeiro: Paz e Terra, 2015.

FREUD, S. O mal-estar na civilização. São Paulo: Penguin Classics Companhia das Letras, 2011.

HARDT, M.; NEGRI, A. Império. Rio de Janeiro: Record, 2005.

LORENZ, K. Civilização e Pecado. Rio de Janeiro: Artenova, 1974.

MBEMBE, A. Necropolítica: biopoder, soberania, estado de exceção e política de morte. Arte \& Ensaios, n. 32, 2016.

MBEMBE, A. Políticas da inimizade. Lisboa: Antígona, 2017.

MBEMBE, A. Crítica da razão negra. São Paulo: Editora N-1, 2018.

MEJÍA, R. E. Micropolíticas, cartografias e heterotopias urbanas: derivas teórico-metodológicas sobre a aventura das (nas) cidades contemporâneas. Revista Espaço Acadêmico, a. XI, n. 132, 2012.

ROLNIK, R. Exclusão territorial e violência. São Paulo em Perspectiva, v. 13, n. 4, 1999. 
SANTOS, M. Por uma geografia nova: da crítica da geografia a uma geografia crítica. São Paulo: Hucitec, 1978. SANTOS, M. Metamorfoses do espaço habitado: fundamentos teóricos e metodológicos da geografia. São Paulo: Edusp, 2014.

SMITH, Neil. The new urban frontier: gentrification and the revanchist city. Londres: Routledge, 1996.

STENGERS, I. No tempo das catástrofes. São Paulo: Cosac Naif, 2015.

TUAN, Y. Paisagens do medo. São Paulo: Unesp, 2005. 